\title{
Cao Guimarães: por uma escrita que se faz enquanto se pensa Rafael de Almeida
}

\section{Resumo}

0 presente texto debruça-se sobre a obra do artista plástico e cineasta Cao Guimarães, interessado nos aspectos estéticos de seus trabalhos e suas implicações políticas latentes. Nosso objetivo é levantar os traços estilísticos mais recorrentes de sua obra cinematográfica, por meio de uma análise de conjunto dos filmes, os quais nos possibilitariam comprovar as aproximações que a totalidade da obra mantém com o filme-ensaio, para, por fim, propormos a percepção da obra cinematográfica de Cao Guimarães enquanto um cinema da superfície, por crer que tal noção permita uma aglutinação entre sua inflexão ensaística e as implicações políticas que acreditamos ser um encadeamento desta.

\section{Palavras-Chave}

Filme-ensaio. Cao Guimarães. Cinema da superfície.

Rafael de Almeida | rafaeldealmeidaborges@gmail.com Doutor em Multimeios pela Universidade Estadual de Campinas Unicamp, Brasil. Professor do Curso de Cinema e Audiovisual da Universidade Estadual de Goiás - UEG, Brasil.
O mais profundo é a pele. Paul Valéry

Em pesquisas anteriores sobre a obra de Cao Guimarães, o nosso objetivo primordial foi construir um percurso analítico da produção do cineasta e artista plástico, que desse a ver as potências expressivas de suas obras, como uma espécie de cartografia de suas poéticas. Por essa perspectiva, cremos ser pertinente traçar algumas linhas que uma análise de conjunto da obra do artista nos permitiria reconhecer. Motivados não por uma aspiração à completude e continuidade, ou por termos o interesse de reduzir sinteticamente todo o trajeto em uma outra coisa, mas para continuar experimentando e refletindo sobre o que vimos o nosso pensamento encontrar junto às obras durante 0 processo de escrita.

\section{Nuances da forma}

0 apelo estético talvez seja a primeira característica que salta aos olhos de qualquer um que se depara com o trabalho de Cao Guimarães. Sua atenção para a potencialidade poética 
dos gestos das formas-de-vida no mundo e, em especial, o modo como agencia os elementos que compõem suas narrativas é o que nos afeta, e seduz, em um primeiro instante. Ou seja, antes de se aprofundar, por meio da verbalidade, nos objetos temáticos que são base de criação para suas obras, importa ao cineasta a maneira como a exposição deles é realizada, a forma com que 0 olhar do artista alcança a superfície do que vê e a materializa. De tal modo, acreditamos que refletir acerca de seu tratamento formal e estético é uma maneira de pensar também sobre as ferramentas das quais se vale 0 cineasta para imprimir seus discursos, declaradamente líricos; de pensar o que a forma nos diz, de si mesma e do mundo.

a) Colagem: A partir de The eye land (Cao Guimarães, 2000), e Between - inventário de pequenas mortes (Cao Guimarães, 2000), obras do início de sua carreira, entraremos em contato com uma figura de estilo que, em maior ou menor grau, estará presente no restante de seu trabalho: a colagem. Essa composição da imagem por meio de materiais diversos revela seu valor estético menos pela desenvoltura do artista em reordenar as várias fontes com as quais trabalha, do que pelos rastros deixados pelas próprias imagens ao se relacionarem com o novo sentido criado durante a montagem. Ao reservar certa autonomia, as imagens atuam também como testemunhas, ou evidências, de que não foram produzidas para aquele fim. Mas se permitem empenhar o papel almejado pelo artista, que as desloca de seu lugar original para alcançar um sentido que não está dado nelas à primeira vista.

Fragmentos de notas imagéticas em um despretensioso diário filmado convertem-se em reflexões sobre a vida e a morte: se em The eye land o desejo melancólico de partilha da existência, da vida, é "impedido" pela distância, pelo exílio, em Between, é a ampliação do conceito de morte que nos faz perceber sua presença constante em tudo, sempre nos deslocando do espaço da vida. Em Volta ao mundo em algumas páginas (Cao Guimarães, Rivane Neuenschwander, 2002), a colagem também é o fator estético predominante e, não por acaso, 0 filme pensa 0 conceito de deslocamento, de viagem, de mudança.

\section{Em Cao Guimarães, a colagem atua como} figura da desterritorialização. 0 deslocamento das imagens, ou melhor, 0 abandono de seus lugares semânticos de origem e sua indissociável construção de um novo espaço de sentido está frequentemente ligado a outros tipos de trânsito. A colagem geralmente opera em suas obras como representação visual de processos de deslocamento, em curso, de sujeitos que atuam como personagens, do próprio artista, ou de ambos. Em extensão a isso, percebemos a colagem, em alguma medida, como sinal estético de um interesse temático do artista pelo errante, pelo nômade, pelo desterritorializado por excelência. Formas-de-vida que serão experimentadas de 
maneira bastante significativa em A alma do osso (Cao Guimarães, 2004) e Andarilho (Cao Guimarães, 2007), por exemplo.

b) Mescla de suportes: Como desdobramento disso, a mescla de suportes (super-8 $\mathrm{mm}, 16 \mathrm{~mm}$, digital) aparece como outro traço estilístico recorrente na obra do artista, sobretudo em $O$ fim do sem fim (Beto Magalhães, Cao Guimarães, Lucas Bambozzi, 2000) e Acidente (Cao Guimarães, Pablo Lobato, 2006). A preocupação com a pureza da linguagem é trocada pela possibilidade de extrair as potências expressivas oferecidas por diferentes suportes em virtude da construção narrativa. E logo, entre eles, por meio da mescla desses formatos, novos significados surgem, o que, ao mesmo tempo, promove uma reflexão acerca dos estados da imagem no interior das obras, por um lado; e uma aproximação do homem às "coisas do mundo", pela anulação do caráter figurativo baseado na lógica mimética da representação, por outro.

Se em Acidente a valorização do banal, do ordinário, do cotidiano se dá por meio da força do acaso e da espera pelo acontecimento, gerenciados pelo dispositivo a que se submete, os sentidos construídos não deixam de estar perpassados e reforçados pelas diferentes cores e texturas impressas pelos suportes utilizados durante 0 registro. Essa mescla nos garante a sensação de estar diante de um álbum de fotografias, construído por um olhar pessoal durante muitos anos, com distintos equipamentos, de maneira tal que seja possível manter um contato visual e sensório não somente com resquícios do passado e memória, mas também com afetos difusos no tempo.

As formas-de-vida que resistem à lógica de trabalho - e aos modos convencionais de pensar, inclusive por meio da criação de gambiarras -, imposta pelo mercado de $O$ fim do sem fim, mantêm uma relação de analogia direta com 0 resgate e 0 uso de suportes não usuais, como 0 super-8 mm e o $16 \mathrm{~mm}$, na realização do filme. Tanto um quanto o outro imprimem um ato de resistência às forças que 0 colocam fora da ordem. E, por outro lado, ao dar a ver um regime heterogêneo de imagens, a obra potencializa o processo de singularização desses sujeitos para além de seus gestos, evidencia e alerta pela hibridização que nossa vista alcança apenas uma imagem, imaterial por natureza, e para além dela há um indivíduo, uma forma-de-vida.

\section{c) Exploração de elementos da natureza:}

Uma outra recorrência estética na obra do cineasta é a exploração de materiais de composição provenientes da natureza. Concerto para clorofila (Cao Guimarães, 2005) talvez seja o exemplo mais representativo dentro de seu repertório, por ser um filme constituído plenamente a partir desta observação e escritura 
por meio de tais elementos. 0 interesse normalmente está centrado menos em lançar um olhar objetivo sobre as figuras da natureza do que propor um jogo formal com elas, que pode, inclusive, levar à abstração completa, revelando um amplo espectro de variação de forma, luz, cor, movimento, etc. $\mathrm{E}$ assim tais imagens, em alguma medida, parecem sempre evidenciar seu caráter de fabricação, para lembrar-nos que se há alguma fidelidade, ela está menos no referente do que em quem as manipula. Por isso aqui, e praticamente em toda a obra do artista, encontraremos um forte apelo às composições visuais através da fotografia, além de manipulação de luz, textura, cor, etc.

E, nesse sentido, cremos que a atenção depositada nesses microdramas da forma na natureza pontuase como uma maneira de criar metáforas visuais que dê vazão aos processos de subjetivação do artista, metáforas que colocam em primeiro plano os movimentos enfrentados pelo cineasta no intuito de transformar a obra em um espaço que possibilita um verdadeiro diálogo entre espectador e realizador. Esse olhar que se lança sobre as paisagens, e simultaneamente as transforma, revela o ver como ferramenta de conhecimento e aponta para a nossa necessidade de reeducar a visão: resistência à lógica do espetáculo e ao bombardeio de imagens. Em Histórias do nãover (Cao Guimarães, 2001), a explicitação dessa preocupação do artista, latente na maioria de seus trabalhos, alcança os níveis mais elevados.
Se, para Deleuze, as imagens de paisagens da natureza poderiam atingir uma emancipação que garante uma similitude entre o real e 0 imaginário, o sujeito e o objeto, o mundo e o eu (Deleuze, 2007, p. 26), não poderíamos deixar de pensar que, em Cao Guimarães, tal recorrência estética se constitui como sinal, como indício visual, do desejo do artista em revelar uma voz que seja pessoal, uma voz que se experimenta através das imagens. E talvez por essa razão Cao se enamore do silêncio, em detrimento da verbalidade, ao propor-se partilhar visualmente o que aprende do mundo à medida que 0 vê, ao convidar-nos a uma leitura dos estratos da imagem enquanto realiza o mesmo exercício, ao expor seu pensamento ao mesmo tempo que ele toma forma.

\section{d) Disjunção imagético-sonora: Por} outro lado, se há uma preferência pela presença comedida da fala ou ausência da verbalidade excessiva, é bom registrar que essa observação silenciosa do mundo investe em uma forte relação com a banda sonora. E é nessa relação que pensamos encontrar mais uma característica marcante do trabalho de Guimarães. Seu trabalho é definido por uma considerável disjunção entre som e imagem. Ambas as imagens, visual e sonora, menos que se relacionarem de maneira hierárquica e submeterem-se aos poderes uma da outra, provocam associações pouco evidentes ao sustentar diálogos intensamente criativos, os quais nos conduzem a novos 
estados de consciência, de compreensão, de pensamento. Acreditamos que essa relação, em alguma medida, afirma a impossibilidade de que 0 espectador efetue apenas uma ligação automática entre as bandas sonora e imagética, exigindo uma outra postura diante daquilo que vê e ouve, uma postura essencialmente crítica.

Caso nos lembremos de $A$ alma do osso, para exemplificar, e de todo o bloco inicial em que somos imersos na paisagem falsamente silenciosa do ermitão, com ausência de falas, os pilares de sustentação da narrativa estão calcados basicamente nas ligações flutuantes entre som e imagem; é evidente que as relações entre banda sonora e visual não estão dadas nem plenamente construídas. Logo, são nas fissuras dessas associações que se instalam as incertezas que nos levam a avançar cada vez mais na narrativa, a entrar no jogo proposto pelo realizador de uma maneira ativa, cumprindo o papel dúbio de crer, mas, ao mesmo tempo, duvidar da imagem que se forma entre nossa visão e audição.

Além disso, o trabalho do duo $O$ Grivo, geralmente responsável pelo tratamento sonoro dos filmes de Cao Guimarães, atua pela ação de figuras estéticas que carregam sensações multiplicadoras do sentido. Ou seja, entre imagem visual e sonora não são firmadas simples relações de oposição, por exemplo, mas combinações complexas, múltiplas e variáveis, as quais dão a ver um panorama infinito de configurações transitórias possíveis. Logo, não há interesse em fazer com que as obras sejam construções fechadas que emitam verdades acerca do mundo. A ânsia por tais verdades é renunciada em virtude da errância do pensamento. Ao flertar com 0 efêmero e o mutável, os filmes de Cao Guimarães se abrem à ficcionalização e expressam um desejo de que suas capacidades de renovação e expansão de sentido sejam mantidas vivas. E, assim, as obras se tornam verdadeiras não por seu caráter predominantemente documental, mas pelo percurso do pensamento do artista compartilhado com 0 espectador.

e) Temporalidade dilatada: 0 próximo aspecto que destacamos está relacionado à temporalidade dilatada presente nas obras, que 0 cineasta efetua ao distender a duração dos planos, geralmente fixos, durante a realização das tomadas, permitindo-nos acompanhar o tempo de uma maneira muito próxima ao que ele foi apreendido; ou torná-las mais lentas por meio da montagem, modificando a velocidade do nosso olhar. Hypnosis (Cao Guimarães, 2001), Da janela do meu quarto (Cao Guimarães, 2004) ou Peiote (Cao Guimarães, 2006) exemplificam perfeitamente esse segundo modo, enquanto Acidente ou Andarilho cumprem tal função para o primeiro. Em um caso ou outro, o que tal aspecto nos põe em questão é a necessidade de alterar a percepção que temos das coisas do mundo ao desejar "eternizar o transitório" (Adorno, 2003, 
p. 27), pois, para que isso aconteça, é necessário que as imagens durem.

Em sua busca por atingir o mutável, 0 efềmero, 0 transitório, por meio da duração, Andarilho revela mais que a existência de homens ordinários em fluxo acompanhados da solidão; evidencia que, para além das relações que eles mantêm com o mundo serem contingentes, os próprios componentes que 0 constituem também 0 são. Logo, embriagados pela experiência sensória com o tempo e tomados por um devir-outro, não nos resta outra opção senão sentir e compreender a própria existência como fragmento, como trecho, como extrato. Paradoxalmente, experimentar a abundância do tempo nas imagens nos faz refletir sobre a brevidade em que ele se manifesta, ou é permitido manifestar-se, cotidianamente, em nossas vidas.

E ao durar, ao resistir, ao permanecer, além de se abrirem à falsificação, ou permitirem que alguma relação entre quem filma e é filmado, entre espectador e obra, seja estabelecida - como já expusemos em momentos distintos, as imagens fazem com que suas maiores potências invistam não em sua própria matéria, mas no pensamento (Brasil, 2010, p. 172). Com o transcorrer do tempo, é possível deslizar pela imagem e esta aparece como um devir, como um fluxo, que está em vias de alterar-se em algo, e que, no entanto, não se modifica efetivamente, senão em nossa própria percepção, em que se altera permanentemente, onde a paisagem está sempre se tornando outra pela ação transformadora do olhar. E, assim, através do tempo, nas obras de Cao Guimarães, os conceitos partem e se apresentam imprecisos, inacabados, incompletos, mas sem recear 0 fracasso da completude, uma vez que, como veremos, cada fragmento irá se relacionar, através da montagem, com os demais e com o todo por relações de vizinhança (Lopes, 2003, p. 176), as quais serão responsáveis por torná-los mais determinados, mais nítidos, por meio do próprio entrelaçar.

f) Montagem de proposições: Tratando, então, do modo como os elementos são agenciados na montagem com vistas à criação de sentido, percebemos que, de modo geral, o interesse em criar uma continuidade espaço-temporal é substituído por um livre arranjo dos materiais que dê a ver um fluxo discursivo. Esse fato, obviamente, está relacionado com o caráter de colagem que já expusemos. Ou seja, de maneira geral, os filmes de Cao Guimarães, normalmente, experimentam com a conexão entre as imagens, desnaturalizando 0 automatismo de tal vínculo, fazendo com que eles apareçam como uma operação do pensamento que convida o espectador a experimentar novas formas de ver.

Esse operar por relações de vizinhança, nesse sentido, muito raramente será limitado por questões de ordem espaço-temporal, deslocandose fluidamente por eles em favor da construção de um discurso orientado por ligações de paridade e 
dinâmicas dialógicas, as quais ocorrem graças a uma montagem propositiva (Weinrichter, 2007), que assume 0 direito de articular livremente imagens e sons em busca de sentidos inesperados, que serão edificados a partir desses encontros.

Rua de mão dupla (Cao Guimarães, 2002) torna-se exemplar para revelar a potência dessa montagem propositiva operada pelo cineasta, ao ser realizado apenas com imagens gravadas pelos participantes do dispositivo criado pelo artista.

Se, por um lado, não ter 0 controle sobre a captação dificultaria a construção narrativa, por outro, ter o total domínio do processo de montagem dessas imagens alheias possibilita ao artista reescrever a história e assegurar uma distância reflexiva - a qual será buscada pelo realizador em todas suas obras, independentemente das imagens terem sido ou não apreendidas por ele -, que imprime uma veia ensaística sem a necessidade de uma voz verbal. E assim acompanhamos um jogo de poder em que a composição dos materiais opera em, ao menos, dois níveis propositivos distintos: aquele em que os fragmentos de um mesmo indivíduo são ordenados para evidenciar o seu próprio olhar acerca do ambiente do outro, e, de modo perspicaz, revela a sombra de si projetada no outro; e outro em que esses mesmos fragmentos se relacionam com os que são exibidos simultaneamente na tela ao lado, para questionar, comparar, estabelecer analogias e diferenças, deduzir ou generalizar as relações mantidas pelos indivíduos que trocaram de casa durante as 24 horas. Distante de ser uma atividade inconsciente, o jogo associativo da montagem mostra-se especialmente sagaz e assertivo, alterando o valor e a potência das imagens de acordo, unicamente, com seus próprios objetivos.

g) Dispositivo1: Por fim, destacaríamos a noção de dispositivo, que impulsiona, em medidas distintas, a criação de obras como Histórias do não-ver, Word/World (Cao Guimarães, 2001), Volta ao mundo em algumas páginas, Rua de mão dupla, Acidente, Quarta-feira de cinzas (Cao Guimarães, 2006), e, nos arriscaríamos a dizer, até mesmo Ex isto (Cao Guimarães, 2010). ${ }^{2}$ Acreditamos que a criação

A partir de Foucault, consideramos dispositivo como "um conjunto diverso que abarca discursos, instituições, decisões regulamentares, leis, medidas administrativas, enunciados científicos, proposições filosóficas etc.". Por essa perspectiva, "0 dispositivo seria a rede capaz de estabelecer relações entre estes elementos", pois, "possuindo uma natureza essencialmente estratégica, sempre lidará com relações de força, instaurando um jogo de poder, com interesses diversos". Dessa forma, os dispositivos sempre provocarão processos de subjetivação nos indivíduos afetados por eles, "cada dispositivo fará com que esses indivíduos produzam o seu sujeito singular, que de forma alguma é universal, mas sim um processo, imanente a todo e qualquer dispositivo" (Almeida, 2016, p. 13). Ao realizar obras que consideramos filmes-dispositivo, Cao Guimarães "recorta um espaço, um tempo, um tipo e/ou uma quantidade de atores e a esse universo acrescenta uma camada que forçará movimentos e conexões", fazendo, dessa forma, com que o processo de feitura da obra vacile em dois extremos opostos e complementares: um de extremo controle, "regras, limites, recortes", e outro de abertura incondicional, "dependente da ação dos atores e de suas interconexões" (Migliorin, 2005, p. 145-146).

Pensamos que, ao dirigir João Miguel, apenas com a sugestão de linhas gerais, sem, no entanto, guiá-lo - inclusive não tendo feito um roteiro para auxiliar 0 ator na construção do personagem -, Cao Guimarães o convoca a participar de um dispositivo. A respeito do filme, ver "Ex Isto, de Cao Guimarães, e o ultrapassamento de si". In: Galáxia (São Paulo), n. 28, dez. 2014. 
inspirada por essas linhas de força, poder e resistência, as quais dão forma às obras, variando entre a total abertura e 0 extremo controle, sinaliza formalmente 0 interesse declarado do artista pelo acaso.

A partir do dispositivo, geralmente motivado por uma intuição, 0 cineasta partilha com 0 espectador o processo - e as reflexões a que se submete durante o mesmo - de uma busca em que a maior ênfase está nas experiências vivenciadas durante o percurso, e não nos resultados ou objetos finais encontrados. Desse modo, por mais que 0 artista, por vezes, alegue não trabalhar com roteiros, pensamos que há sempre a existência de um roteiro mínimo que será responsável por orientar processos de criação em aberto.

E por outro lado, fazendo eco a Comolli (2008, p. 169), ao valer-se de estratégias de criação provenientes do dispositivo, Cao Guimarães abre sua prática artística ao mundo e vai ao encontro do aleatório, das fissuras do real, do acontecimento, de vestígios que não importam às narrativas fabricadas pelos grandes meios. Sendo assim, a fuga à roteirização configura-se também como uma negação às construções fechadas do mundo e será acompanhada pelo risco do fracasso, e de tal risco extrairá sua força e potência.

\section{2 (Re)ver}

Enquanto traçamos as linhas anteriores, reconhecíveis a partir do tratamento formal e estético dos filmes, revendo, reafirmando e aprimorando muito dos apontamentos que elaboramos em outros textos, nosso interesse foi de evidenciar, aos poucos, o quanto o trabalho do artista apresenta uma inflexão ensaística que, ao mesmo tempo, revela uma série de implicações políticas latentes nos discursos construídos. Ou seja, o modo ensaístico assumido por Cao Guimarães, em níveis muito variáveis no conjunto das obras, articula a forma e a estética com 0 histórico e o político (Alter, 1996, p. 166).

A título de comprovação, caso relacionássemos cada figura estética elencada anteriormente às suas reverberações que a aproximam, direta ou tangencialmente, à forma ensaística, perceberíamos que: a) a partir da colagem, passamos a compreender o corte como interstício, isto é, como espaço para colocar o pensamento no interior das imagens que substitui a simples associação delas; b) a mescla de suportes revela, como já apontamos, uma reflexão sobre o caráter metamórfico das imagens, ou seja, sobre a matéria a ser moldada na construção do discurso; c) a exploração de materiais de composição provenientes da natureza insere visualmente uma reflexividade personificada na figura do artista, e expõe, em outra mão, $o$ interesse de imprimir uma voz pessoal, de modo geral, que busca seu lugar entre as imagens; d) a disjunção imagéticosonora, com suas colisões entre as duas bandas, gera fraturas que instauram a dúvida e convocam a existência de um espectador ativo 
e crítico; e) a tentativa de captar e eternizar 0 mutável, 0 efêmero e 0 transitório aparece por meio da temporalidade dilatada; f) a montagem de proposições instala tal intervenção fora das convenções espaço-temporais, e a caracteriza efetivamente como uma operação do pensamento; g) por fim, a abertura para 0 acaso e 0 interesse pelo processo aparecem vinculados à noção de dispositivo.

Se rever, voltar a ver, a imagem é a condição necessária para que o cinema se produza como ensaio, de acordo com Antonio Weinrichter (2007, p. 28), perceberíamos que, de modo geral, tudo que apontamos anteriormente converge para tal movimento do olhar. E, assim, por mais que seja pouco usual em sua obra a mediação de uma voz verbal para criar a distância necessária do sentido original da imagem, como é recorrente em filmes-ensaio, acreditamos que tal afastamento é alcançado em Cao Guimarães ao trabalhar com suas imagens como se não fossem suas, manipulando-as, moldando-as de acordo com objetivos que não estão presentes nelas de antemão, mas que surgem do contato da matéria com as mãos do artista, que esculpe as imagens no sentido do sentido, como resultado de um trabalho de pensamento.

Essa inflexão ensaística, como já sinalizamos, evidencia encadeamentos de ordem política. 0 que não significa dizer que isso se justifique, tão-somente, pelo interesse do artista por formasde-vida, lugares e assuntos que, em grande parte, estão às margens da esfera midiática. No entanto, principalmente pela capacidade das obras em favorecer transformações na maneira em que percebemos e compreendemos o mundo e criar diferentes formas de experiência com o sensível, que, através de uma tomada de consciência, podem nos levar à mobilização política (Rancière, 2010, p. 110), pensamos que, ao valorizar elementos que pertencem à ordem do banal, do ordinário, do cotidiano; ou eleger como personagens indivíduos que resistem à lógica de trabalho imposta pela lógica do capital; ou tratar da necessidade de reeducar a visão, resistindo à lógica do espetáculo e ao bombardeio de imagens; ou, ainda, ao se dedicar às gambiarras e à resistência aos modos convencionais pelos quais atua nosso pensamento, Cao Guimarães, sobretudo, cria dispositivos artísticos que induzem a processos de subjetivação política, enquanto nos propõem 0 aprimoramento de nosso olhar.

\section{A superfície, antes de nada}

A nossa hipótese é de que 0 cinema de Cao Guimarães registra, antes de tudo, superfícies.

Presta-se a filmar a pele das formas-de-vida, lugares e do mundo não para simplesmente descobrir o que se passa por detrás dela, senão para tentar tocar o interior de sua espessura, alcançar essa parte escondida que, apesar de estar exposta em sua superfície, somos geralmente incapazes de enxergar. Superfície aqui compreendida não como simples oposição à profundidade, mas à interpretação (Deleuze, 
1992, p. 109). Afinal, como nos lembra Cezar Migliorin, "a profundidade frequentemente traz a limpeza que subtrai o ser. A complexidade do ensaio é frequentemente de superfície, operando em extensão, por montagem" (Migliorin, 2010, p. 22). Por esse motivo, nos permitimos compreender o trabalho de Cao Guimarães enquanto cinema da superficie, que, ao invés de interpretar 0 mundo, em busca de uma essência escondida, o experimenta. Circunstanciemos.

Se, segundo Adorno, o "pensamento é profundo por se aprofundar em seu objeto, e não pela profundidade com que é capaz de reduzi-lo a uma outra coisa" (Adorno, 2003, p. 27), acreditamos, por consequência, que as imagens produzidas pelo artista, que não deixam de organizar-se ensaisticamente enquanto formas que pensam, refletem a dedicação do olhar ao se embrenhar pela extensa área do invólucro das coisas do mundo sem a intenção de restringi-las, sintetizálas ou dominá-las.

Nesse sentido, em Cao Guimarães, com 0 investimento no envoltório sensível dos seres, o cinema concorda em assumir seu papel de superfície através da qual 0 artista tenta revelar de novas maneiras a existência e a experiência de formas-de-vida em sua singularidade, que, normalmente, como vimos, estão marginalizadas nos contextos social e econômico.

Ou seja, em alguma medida, acreditamos que a percepção da obra do artista enquanto cinema da superfície permite uma aglutinação entre sua inflexão ensaística e as implicações políticas que cremos ser um encadeamento desta. Isso pois, se, por um lado, a distância íntima instaurada entre realizador e imagem, requisitada pelo ensaio, intensifica uma relação entre ambos por meio da superfície que salta à forma do filme, por outro, a partir de Rancière (2009), a superfície revela-se como uma forma de partilha do sensível, logo lugar político.

\section{Por uma escrita que se faz enquanto se pensa}

Compreender a noção de ensaio nas obras de Cao Guimarães significa não somente se dar conta da liberdade de pensamento que acompanha 0 cineasta; das distâncias que toma de um olhar que se pretende objetivo; da fragmentação que constrói um discurso heterogêneo geralmente incompleto, inacabado, inconcluso. Todavia, perceber que, junto a esse processo reflexivo, está o desejo pelo outro - pelas cores e pelos sons do outro, pela vida do outro, pelos mundos possíveis e habitáveis do outro -, sempre impulsionando devires capazes de transformar seus filmes em singelos atos afetivos.

Se a estrutura básica do filme ensaístico reside em uma reflexão por meio de imagens, elaborada por uma série de ferramentas retóricas, construídas simultaneamente ao processo de reflexão, conforme nos diz Josep M. Català (2005, p. 133), essa escrita que se faz enquanto se pensa, esse 
pensamento que é exposto durante o processo em que toma forma, permite que as obras assumamse como fluxos de vida, frutos de um olhar afetuoso, pessoal e político, consciente do valor da exposição que materializa.

Os afetos que embalam os desejos do cineasta e 0 levam a atravessar esses devires não 0 abandonam na fase de montagem, induzindo o modo de fazer do artista e possibilitando que a superfície dos filmes seja tomada por uma complexa configuração afetiva, a qual expande seus sentidos e cria intensos espaços dialógicos que convocam à ação espectadores ativos. Nesse sentido, as imagens geradas, senão encadeiam alterações imediatas de consciência política, por meio do afeto são capazes de auxiliar na construção de "configurações novas do visível, do dizível e do pensável, e, por essa via, uma nova paisagem do possível" (Rancière, 2010, p. 151), tarefa que cumprem, como nos lembra Rancière, sem antecipar seu sentido ou efeito.

\section{Referências}

ADORNO, Theodor. 0 ensaio como forma. In: Notas de literatura I. São Paulo: Duas Cidades; Ed. 34, 2003.

ALMEIDA, Rafael de. Aquele eu que vejo no outro: 0 dispositivo em Rua de Mão Dupla, de Cao Guimarães. In: MARTINS, Alice Fátima; SATLER, Lara Lima (Orgs.). Imagens, olhares, narrativas. Curitiba, PR: CRV, 2016.

Ex Isto, de Cao Guimarães, e 0

ultrapassamento de si. Galáxia (São Paulo, Online), n. 28, dez. 2014.
ALTER, Nora. The political im/perceptible in the Essay Film: Farocki's "Images of the World and the Inscription of War". New German Critique, No. 68, Special Issue on Literature. Spring - Summer, 1996.

BRASIL, André. Ensaios de uma imagem só. In: MIGLIORIN, Cezar (Org.). Ensaios no real. Rio de Janeiro: Beco do Azougue, 2010.

CATALÀ, Josep M. Film-ensayo y vanguardia. In: CERDÁN, Josetxo (Org.); TORREIRO, Casimiro (Org.).

Documental y vanguadia. Madrid: Cátedra, 2005.

COMOLLI, Jean-Louis. Ver e poder: a inocência perdida - cinema, televisão, ficção, documentário. Belo Horizonte: Editora UFMG, 2008.

DELEUZE, Gilles. A imagem-tempo. São Paulo: Brasiliense, 2007. Rachar as coisas, rachar as palavras. In: Conversações, 1972-1990. São Paulo: Ed. 34, 1992.

LOPES, Silvina Rodrigues. Do ensaio como pensamento experimental. In: Literatura, defesa do atrito. Lisboa: Vendaval, 2003.

MIGLIORIN, Cezar. Documentário recente brasileiro e a política das imagens. In: Ensaios no real. Rio de Janeiro: Beco do Azougue, 2010.

Filme-dispositivo: Rua de mão dupla, de Cao Guimarães. In: CATANI, Afrânio Mendes [et al.](Orgs.). Estudos Socine de Cinema, Ano VI. São Paulo: Nojosa Edições, 2005. P. 143-150.

RANCIÈRE, Jacques. A partilha do sensível: estética e política. São Paulo: EXO experimental org.; Editora $34,2009$.

0 espectador emancipado. Lisboa: Orfeu Negro, 2010.

WEINRICHTER, Antonio. Un concepto fugitivo: notas sobre el film-ensayo. In: La forma que piensa: tentativas en torno al cine ensayo. Pamplona: Gobierno de Navarra, 2007. 


\begin{tabular}{|c|c|}
\hline $\begin{array}{l}\text { Cao Guimarães: for a writing } \\
\text { that is done while thinks itself }\end{array}$ & $\begin{array}{l}\text { Cao Guimarães: por una escrita } \\
\text { que se hace mientras se piensa }\end{array}$ \\
\hline $\begin{array}{l}\text { Abstract } \\
\text { This paper focuses on the work of the artist and } \\
\text { filmmaker Cao Guimarães, interested in the aesthetic } \\
\text { aspects of their work and their latent political } \\
\text { implications. Our goal is to raise the most recurrent } \\
\text { stylistic traits of his film work, through a film overall } \\
\text { examination, which would enable us to verify the } \\
\text { approaches that the entire work remains with the } \\
\text { film-essay, to finally propose the perception of the } \\
\text { cinematographic work of Cao Guimarães while a } \\
\text { cinema of surface, to believe that such a notion } \\
\text { allow an agglutination between his essayistic } \\
\text { inflection and political implications that we believe to } \\
\text { be a thread of this. } \\
\text { Keywords } \\
\text { Film-essay; Cao Guimarães; Cinema of surface. }\end{array}$ & $\begin{array}{l}\text { Resumen } \\
\text { El presente texto debruza-se sobre la obra del artista } \\
\text { plástico y cineasta Cao Guimarães, interesado } \\
\text { en los aspectos estéticos de sus trabajos e sus } \\
\text { implicaciones políticas latentes. Nuestro objetivo } \\
\text { es levantar los rasgos estilísticos más recurrentes } \\
\text { de su obra cinematográfica, por medio de una } \\
\text { análisis de conjunto de las películas, que nos } \\
\text { permitirían comprobar las aproximaciones que la } \\
\text { totalidad de la obra mantiene con el film-ensayo, } \\
\text { para, por fin, proponernos la percepción de la obra } \\
\text { cinematográfica de Cao Guimarães mientras un cine } \\
\text { de la superficie, por creer que tal noción permita } \\
\text { una aglutinación entre su inflexión ensayística y } \\
\text { las implicaciones políticas que acreditamos ser un } \\
\text { encadenamiento de esta. } \\
\text { Palabras clave } \\
\text { Film-ensayo; Cao Guimarães; Cine de la superficie. }\end{array}$ \\
\hline
\end{tabular}




\section{Expediente}

A revista E-Compós é a publicação científica em formato eletrônico da Associação Nacional dos Programas de Pós-Graduação em Comunicação (Compós). Lançada em 2004, tem como principal finalidade difundir a produção acadêmica de pesquisadores da área de Comunicação, inseridos em instituições do Brasil e do exterior.

\section{E-COMPÓS I www.e-compos.org.br I E-ISSN 1808-2599}

Revista da Associação Nacional dos Programas de Pós-Graduação em Comunicação.

Brasília, v.19, n.1, jan./abr. 2016.

A identificação das edições, a partir de 2008, passa a ser volume anual com três números.

Indexada por Latindex I www.latindex.unam.mx

\section{CONSELHO EDITORIAL}

Alexandre Farbiarz, Universidade Federal Fluminense, Brasil Alexandre Rocha da Silva, Universidade Federal do Rio Grande do Sul, Brasil Ana Carolina Damboriarena Escosteguy, Pontifícia Universidade Católica do Rio Grande do Sul, Brasil

Ana Carolina Rocha Pessôa Temer, Universidade Federal de Goiás, Brasil Ana Regina Barros Rego Leal, Universidade Federal do Piaú, Brasil Andrea França, Pontifícia Universidade Católica do Rio de Janeiro, Brasil André Luiz Martins Lemos, Universidade Federal da Bahia, Brasil Antonio Carlos Hohlfeldt, Pontifícia Universidade Católica do Rio Grande do Sul, Brasil

Arthur Ituassu, Pontifícia Universidade Católica do Rio de Janeiro, Brasil Álvaro Larangeira, Universidade Tuiuti do Paraná, Brasil

Ângela Freire Prysthon, Universidade Federal de Pernambuco, Brasil César Geraldo Guimarães, Universidade Federal de Minas Gerais, Brasil Cláudio Novaes Pinto Coelho, Faculdade Cásper Líbero, Brasil Daisi Irmgard Vogel, Universidade Federal de Santa Catarina, Brasil Denize Correa Araujo, Universidade Tuiuti do Paraná, Brasil Eduardo Antonio de Jesus, Pontifícia Universidade Católica de Minas Gerais, Brasil

Daniela Zanetti, Universidade Federal do Espirito Santo, Brasil Eduardo Vicente, Universidade de São Paulo, Brasil Elizabeth Moraes Gonçalves, Universidade Metodista de São Paulo, Brasil Erick Felinto de Oliveira, Universidade do Estado do Rio de Janeiro, Brasil Francisco Elinaldo Teixeira, Universidade Estadual de Campinas, Brasil Francisco Paulo Jamil Almeida Marques, Universidade Federal do Paraná, Brasil

Gabriela Reinaldo, Universidade Federal do Ceará, Brasil Goiamérico Felício Carneiro Santos, Universidade Federal de Goiás, Brasil Gustavo Daudt Fischer, Universidade do Vale do Rio dos Sinos, Brasil Herom Vargas, Universidade Municipal de São Caetano do Sul, Brasil Itania Maria Mota Gomes, Universidade Federal da Bahia, Brasil
Janice Caiafa, Universidade Federal do Rio de Janeiro, Brasil Jiani Adriana Bonin, Universidade do Vale do Rio dos Sinos, Brasil José Afonso da Silva Junior, Universidade Federal de Pernambuco, Brasil José Luiz Aidar Prado, Pontifícia Universidade Católica de São Paulo, Brasil Juçara Gorski Brittes, Universidade Federal de Ouro Preto, Brasil Kati Caetano, Universidade Tuiuti do Paraná, Brasil Lilian Cristina Monteiro França, Universidade Federal de Sergipe, Brasil Liziane Soares Guazina, Universidade de Brasilia, Brasil Luíza Mônica Assis da Silva, Universidade de Caxias do Sul, Brasil Luciana Miranda Costa, Universidade Federal do Pará, Brasil Malena Segura Contrera, Universidade Paulista, Brasil Maria Ogécia Drigo, Universidade de Sorocaba, Brasil Maria Ataide Malcher, Universidade Federal do Pará, Brasil Marcia Tondato, Escola Superior de Propaganda e Marketing, Brasil Marcel Vieira Barreto Silva, Universidade Federal da Paraíba, Brasil Maria Clotilde Perez Rodrigues, Universidade de São Paulo, Brasil Maria das Graças Pinto Coelho, Universidade Federal do Rio Grande do Norte, Brasil

Mauricio Ribeiro da Silva, Universidade Paulista, Brasil

Mauro de Souza Ventura, Universidade Estadual Paulista, Brasil Márcio Souza Gonçalves, Universidade do Estado do Rio de Janeiro, Brasil Micael Maiolino Herschmann, Universidade Federal do Rio de Janeiro, Brasil Mirna Feitoza Pereira, Universidade Federal do Amazonas, Brasil Nísia Martins Rosario, Universidade Federal do Rio Grande do Sul, Brasil Potiguara Mendes Silveira Jr, Universidade Federal de Juiz de Fora, Brasil Regiane Regina Ribeiro, Universidade Federal do Paraná, Brasil Rogério Ferraraz, Universidade Anhembi Morumbi, Brasil Rose Melo Rocha, Escola Superior de Propaganda e Marketing, Brasil Rozinaldo Antonio Miani, Universidade Estadual de Londrina, Brasil Sérgio Luiz Gadini, Universidade Estadual de Ponta Grossa, Brasil Simone Maria Andrade Pereira de Sá, Universidade Federal Fluminense, Brasil Veneza Mayora Ronsini, Universidade Federal de Santa Maria, Brasil Walmir Albuquerque Barbosa, Universidade Federal do Amazonas, Brasil

\section{COMISSÃO EDITORIAL}

Cristiane Freitas Gutfreind, Pontifícia Universidade Católica do Rio Grande do Sul, Brasil Irene Machado, Universidade de São Paulo, Brasil

Eduardo Antonio de Jesus, Universidade Católica de Minas Gerais, Brasil

\section{CONSULTORES AD HOC}

Cleusa M. Andrade Scroferneker, Pontifícia Universidade Católica do Rio Grande do Sul, Brasil Francisco Rüdiger, Pontifícia Universidade Católica do Rio Grande do Sul, Brasil Juliana Freire Gutmann, Universidade Federal da Bahia, Brasil Karla Regina M. P. Patriota Bronsztein, Universidade Federal de Pernambuco, Brasil Laura Loguercio Cánepa, Universidade Anhembi Morumbi, Brasil Lucia Isaltina C. Leão, Pontifícia Universidade Católica de São Paulo, Brasil

\section{EQUIPE TÉCNICA}

\section{ASSISTENTE EDITORIAL I Márcio Zanetti Negrini}

REVISÃO DE TEXTOS I Press Revisão

EDITORAÇÃO ELETRÔNICA I Roka Estúdio

CONTATO I revistaecompos@gmail.com

\section{COMPÓS I www.compos.org.br}

Associação Nacional dos Programas de Pós-Graduação em Comunicação

Presidente

Edson Fernando Dalmonte

Programa de Pós-Graduação em Comunicação

e Cultura Contemporânea - UFBA

edsondalmonte@uol.com.br

Vice-presidente

Cristiane Freitas Gutfreind

Programa de Pós-Graduação em Comunicação Social - PUC-RS cristianefreitas@pucrs.br

Secretário-Geral

Rogério Ferraraz

Programa de Pós-Graduação em Comunicação

Universidade Anhembi Morumbi

rogerioferraraz@anhembimorumbi.edu.br 